\title{
Excited-state proton transfer from pyranine to acetate in methanol
}

\author{
SUDIP KUMAR MONDAL, SUBHADIP GHOSH, KALYANASIS SAHU, PRATIK SEN and \\ KANKAN BHATTACHARYYA* \\ Physical Chemistry Department, Indian Association for the Cultivation of Science, Jadavpur, \\ Kolkata 700032 \\ e-mail: pckb@mahendra.iacs.res.in
}

\begin{abstract}
Excited-state proton transfer (ESPT) of pyranine (8-hydroxypyrene-1,3,6-trisulphonate, HPTS) to acetate in methanol has been studied by steady-state and time-resolved fluorescence spectroscopy. The rate constant of direct proton transfer from pyranine to acetate $\left(k_{1}\right)$ is calculated to be $\sim 1 \times 10^{9} \mathrm{M}^{-1} \mathrm{~s}^{-1}$. This is slower by about two orders of magnitude than that in bulk water $\left(8 \times 10^{10} \mathrm{M}^{-1} \mathrm{~s}^{-}\right.$ ${ }^{1}$ ) at $4 \mathrm{M}$ acetate.
\end{abstract}

Keywords. Excited-state proton transfer; pyranine; fluorescence spectroscopy; direct proton transfer.

\section{Introduction}

Proton transfer is fundamental in many natural processes e.g. in abnormally high mobility of proton in water ('Grotthuss mechanism') ${ }^{1}$ and transport of a proton through a membrane. ${ }^{2}$ Dissociation of an acid (HA) in an aqueous solution involves transfer of a proton to a water molecule to form a geminate ion pair consisting of the deprotonated species $\left(\mathrm{A}^{-}\right)$and the hydronium ion $\left(\mathrm{H}_{3} \mathrm{O}^{+}\right)$. Subsequently, the geminate ion pair dissociates to give a solvent-separated ion pair. Excited-state proton transfer (ESPT) of pyranine (8-hydroxypyrene-1,3,6-trisulphonate, HPTS) has been widely studied to explore the mechanism of proton transfer in different media. ${ }^{3-13}$ In the ground state, pyranine is a weak acid $\left(\mathrm{p} K_{a}=7 \cdot 4\right){ }^{3} \mathrm{In}$ the excited state, $\mathrm{p} K_{a}$ value of pyranine decreases to $0 \cdot 4{ }^{3}$ According to a femtosecond fluorescence upconversion study, ESPT of HPTS in water involves three time constant $0.3,2.5$ and $87 \mathrm{ps}$. The 0.3 and $2.5 \mathrm{ps}$ components are ascribed to solvation dynamics and LE-CT transition, respectively while the $87 \mathrm{ps}$ component to the proton dissociation and diffusion in water. ${ }^{4,5}$ More recently, femtosecond mid-IR study suggests that the inter-conversion between the two electronic states of HPTS occurs on a time scale $<150 \mathrm{fs}^{6}{ }^{6}$ The transient response of the $\mathrm{O}-\mathrm{H}$ stretch of HPTS displays two ultrafast components $(0 \cdot 3 \pm$ $0.2 \mathrm{ps}$ and $3 \pm 1.5 \mathrm{ps}$ ) which are assigned to

*For correspondence solvent relaxation affecting the hydrogen bonds between HPTS and water. This is followed by two additional components arising from proton transfer to water $(90 \pm 30 \mathrm{ps})$ and rotational diffusion $(200 \pm$ $50 \mathrm{ps})^{6}$

Proton transfer rate from HPTS to a proton scavenger (i.e. acetate) is very fast. ${ }^{7-9,11}$ Rini et $a l^{9}$ studied ESPT from HPTS to acetate by monitoring the rise of the carbonyl IR band at $1720 \mathrm{~cm}^{-1}$ arising from acetic acid. Rise of this band clearly indicates arrival of the proton at the acetate. They detected very fast ESPT $(<0 \cdot 15 \mathrm{ps})$ for those HPTS which are already hydrogen-bonded to the acetate in the ground state ${ }^{9}$. For the uncomplexed HPTS, diffusion is needed before formation of a H-bond in the excited state and, hence, proton-transfer rate is slower. ${ }^{9,10}$ When a base (e.g. acetate) is introduced into a solution, direct proton transfer to acetate competes with protontransfer rate to the solvent. Genosar et $\mathrm{ll}^{7}{ }^{7}$ studied direct excited-state proton transfer from pyranine to acetate in water in the concentration range of $0.5-4 \mathrm{M}$ acetate. They reported that in the presence of $4 \mathrm{M}$ acetate, the pseudo first-order rate of proton abstraction is $\approx(3 \mathrm{ps})^{-1}$ This corresponds to a rate constant $\approx 8 \times 10^{10} \mathrm{M}^{-1} \mathrm{~s}^{-1}$ and represents one of the fastest intermolecular reactions observed in bulk water. In the present work, we have studied excited-state proton transfer from HPTS (pyranine) to acetate in methanol. We show that in the case of methanol there is no proton transfer from HPTS to methanol (solvent) and we exclusively observe direct proton transfer to acetate. 
Table 1. Picosecond decay parameters of $\mathrm{HA}$ emission (at $420 \mathrm{~nm}$ ) and $\mathrm{A}^{-}$emission (at $515 \mathrm{~nm}$ ) of pyranine (HPTS) in methanol at different acetate concentrations.

\begin{tabular}{lcccc}
\hline & HA emission $^{1}$ & \multicolumn{2}{c}{$\mathrm{A}^{-}$emission $^{1}$} & \\
\cline { 3 - 4 } [Acetate] $(\mathrm{M})$ & decay time $\tau_{1}$ ps $\left(a_{1}\right)$ & Rise time $\tau_{1}$ ps $\left(a_{1}\right)^{*}$ & Decay time $\tau_{2}$ ps $\left(a_{2}\right)$ & Acetic acid added (M) \\
\hline $0 \cdot 00$ & $4000(1 \cdot 0)$ & - & - & 0 \\
$0 \cdot 25$ & $2000(1 \cdot 0)$ & 1950 & $5000(0 \cdot 10)$ & $0 \cdot 02$ \\
$0 \cdot 50$ & $1250(1 \cdot 0)$ & 1200 & $5000(0 \cdot 10)$ & $0 \cdot 23$ \\
$0 \cdot 75$ & $950(1 \cdot 0)$ & 900 & $5000(0 \cdot 09)$ & $0 \cdot 40$ \\
$1 \cdot 00$ & $750(1 \cdot 0)$ & 700 & $5000(0 \cdot 07)$ & $0 \cdot 58$ \\
$1 \cdot 50$ & $600(1 \cdot 0)$ & 500 & $5000(0 \cdot 07)$ & $0 \cdot 93$ \\
$2 \cdot 00$ & $450(1 \cdot 0)$ & 400 & $5000(0 \cdot 06)$ & $1 \cdot 28$ \\
\hline
\end{tabular}

${ }^{1} \pm 10 \%$

$* a_{1}=-a_{2},(4)$

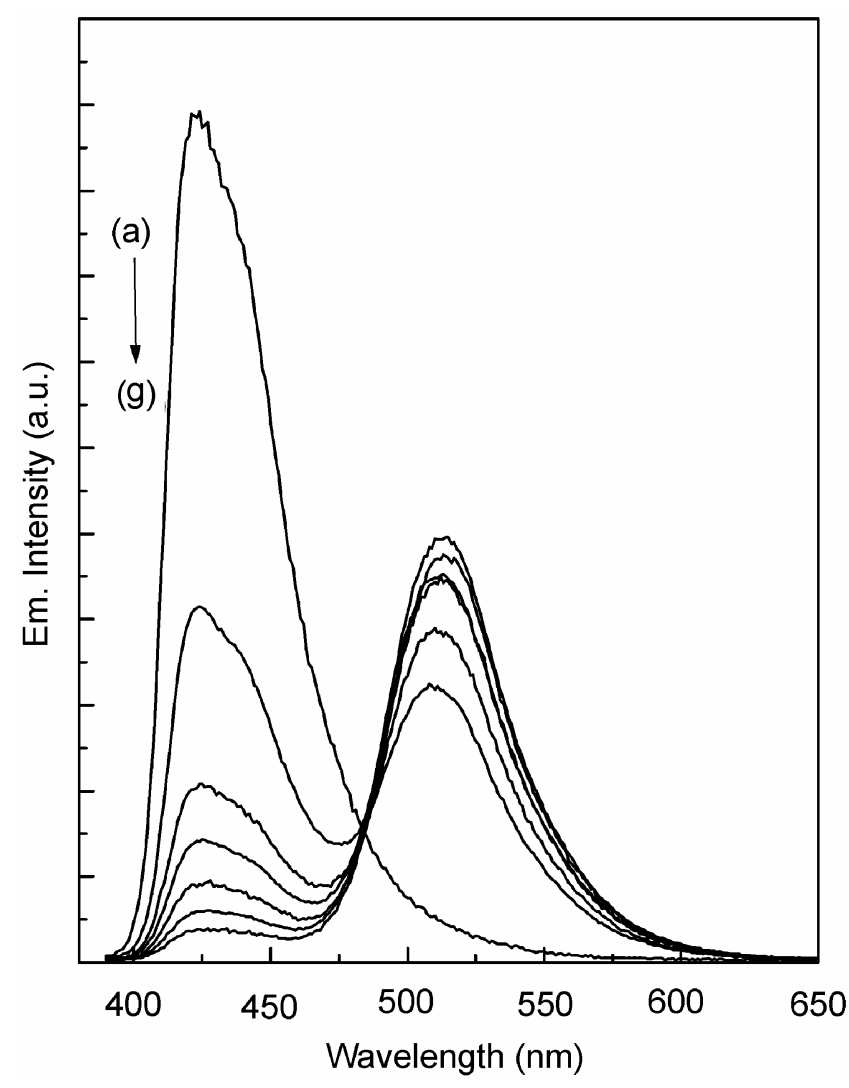

Figure 1. Steady state emission spectra $\left(\lambda_{\mathrm{ex}}=375 \mathrm{~nm}\right)$ of $20 \mu \mathrm{M}$ HPTS $(\mathrm{a}-\mathrm{g})$ in methanol containing $0,0.25$, $0.5,0.75,1,1.5$ and $2 \mathrm{M}$. acetate.

\section{Experimental}

HPTS (Fluka) and methanol (99.7\%, Uvasol, Merck) were used as received. The steady-state absorption and emission spectra were recorded on a Shimadzu UV-2401 spectrophotometer and a Spex FluoroMax3 spectrofluorimeter respectively.
For picosecond lifetime measurements, the samples were excited at $375 \mathrm{~nm}$ using a picosecond diode laser (IBH Nanoled-11) in an IBH Fluorocube apparatus. The emission was collected at magic angle polarization using a Hamamatsu MCP photomultiplier (5000U09). The time-correlated single-photon counting (TCSPC) setup consists of an Ortec 9327 CFD and a Tennelec TC 863 TAC. The data were collected with a PCA3 card (Oxford) as a multi-channel analyser. The typical FWHM of the system response using a liquid scatterer is about 90 ps. The fluorescence decays were deconvoluted using IBH DAS6 software.

\section{Results}

\subsection{Steady state spectra}

In methanol, HPTS exhibits an absorption maximum at $403 \mathrm{~nm}$ due to the protonated form (HA) and no absorption band for the deprotonated form $\left(\mathrm{A}^{-}\right)$is observed. In neat methanol, HPTS shows only one prominent emission peak at $420 \mathrm{~nm}$ due to the protonated form (HA). This indicates that only the HA form exists in the excited state, in methanol.

On addition of sodium acetate, a new absorption band at $\approx 450 \mathrm{~nm}$ arises due to formation of $\mathrm{A}^{-}$. To suppress formation of the anion $\left(\mathrm{A}^{-}\right)$in the ground state (i.e. ground-state proton transfer from HPTS to acetate), requisite amount of acetic acid was added (table 1). In the presence of added acetic acid, there is no noticeable change in the absorption band at about $403 \mathrm{~nm}$ with variation in concentration of sodium acetate.

On addition of sodium acetate, emission intensity of the protonated form of HPTS (at $420 \mathrm{~nm}$ ) decreases with a concomitant increase in the emission 
intensity at $515 \mathrm{~nm}$ due to the formation of deprotonated form (figure 1).

\subsection{Time-resolved studies}

Time-resolved fluorescence decays of the protonated form were monitored at $\lambda_{\mathrm{em}}=420 \mathrm{~nm}$, and for the deprotonated form the decays were recorded at $\lambda_{\mathrm{em}}=515 \mathrm{~nm}$. In pure methanol, the decays at both $420 \mathrm{~nm}$ and $515 \mathrm{~nm}$ are similar and found to be single exponential with a time constant of $\sim 4.0 \mathrm{~ns}$. The absence of a rise at $515 \mathrm{~nm}$ (where the anion $\mathrm{A}^{-}$ emits) clearly indicates that there is no ESPT from HPTS to methanol in the absence of acetate.

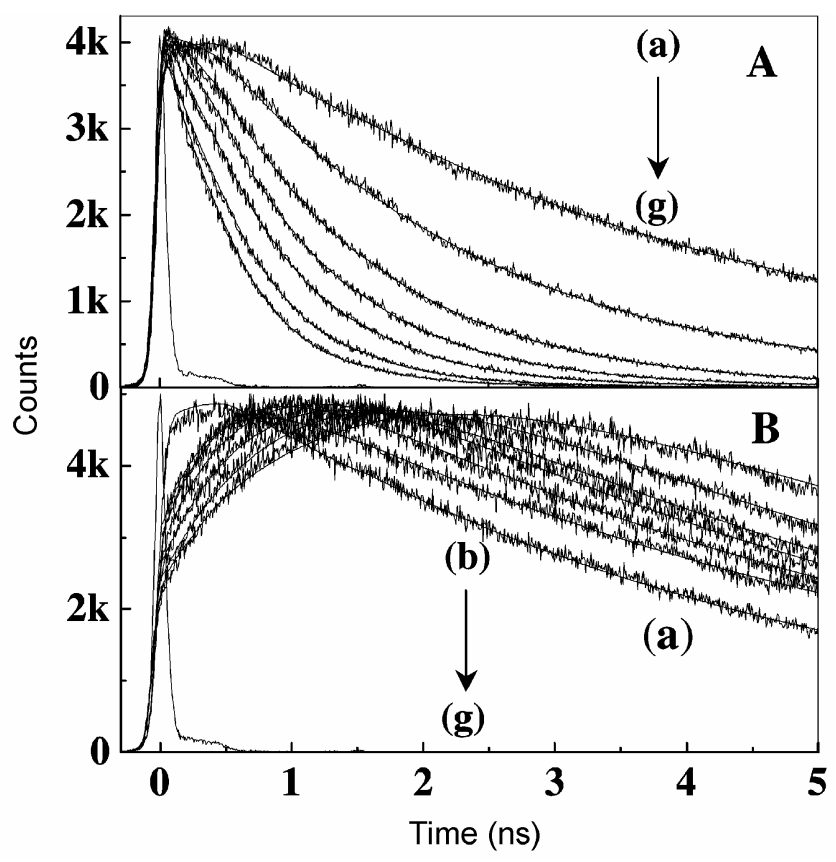

Figure 2. Picosecond transients of HPTS in methanol containing (a-g) $0,0.25,0.5,0.75,1,1.5$ and $2 \mathrm{M}$ sodium acetate at $\lambda_{\mathrm{em}}$ (A) $420 \mathrm{~nm}$ and (B) $515 \mathrm{~nm}\left(\lambda_{\mathrm{ex}}=375 \mathrm{~nm}\right)$.<smiles>COS(=O)(=O)c1cc(O)c2ccc3c(S(=O)(=O)O)cc(S(=O)(=O)O)c4ccc1c2c34</smiles>

Scheme 1. Structure of HPTS (pyranine).
On addition of sodium acetate to a solution of HPTS in methanol, at $515 \mathrm{~nm}$ a distinct rise component precedes the decay. The rise component is a clear indication that the excited-state proton transfer process occurs from HPTS to acetate. The decays at $420 \mathrm{~nm}$ are found to be single exponential for all acetate concentrations $(0 \cdot 25-2 \mathrm{M})$ (figure $2 \mathrm{~A}$, table 1 ).

The decay component at $420 \mathrm{~nm}$ is almost similar to the rise time observed at $515 \mathrm{~nm}$ (figure 2A and $2 \mathrm{~B}$, table 1). The rise time at $515 \mathrm{~nm}$ (or decay at $420 \mathrm{~nm}$ ) gradually decreases with the increase of acetate concentration from $1.95 \mathrm{~ns}$ at $0.25 \mathrm{M}$ acetate to $400 \mathrm{ps}$ at $2 \mathrm{M}$ acetate.

\section{Discussion}

Evidently, in methanol, there is no proton transfer to solvent and direct ESPT from HPTS to the acetate ion takes place. It may be recalled that the rate of proton transfer in bulk water is $\approx 9.4 \times 10^{9} \mathrm{~s}^{-1}$ which is in marked contrast to that in bulk methanol where no ESPT occurs at all. ${ }^{11}$ This is due to the fact that methanol is a very poor proton acceptor compared to water, and hence no methanol-mediated proton transfer takes place. For the solvent to take part in the proton-transfer process, it must stabilise the discharged proton by screening it from the negative charge of the conjugate base, and provide an efficient mode for the diffusion of the proton to the bulk.

To analyse the observed decay characteristics of HPTS in the presence of acetate, we now use a simple kinetic model ${ }^{14,15}$ as follows

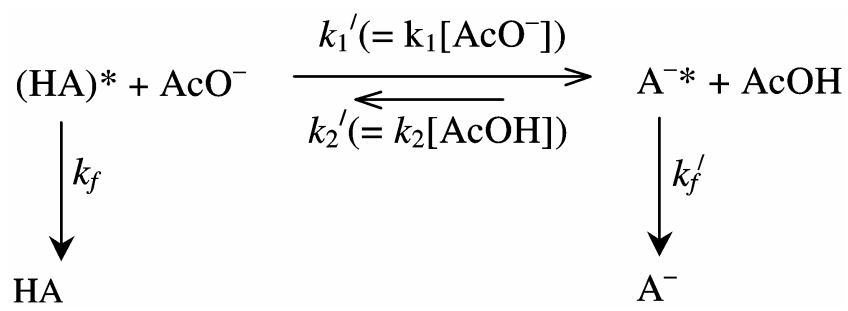

In this case, the excited photoacid $\mathrm{HA}^{*}$ donates its proton directly to the acetate ion to produce $\mathrm{A}^{-*}$. $k_{1}^{\prime}$ and $k_{2}^{\prime}$ are the pseudo-first order rate constants respectively for the forward and backward processes in the excited state. The differential equations corresponding to the above scheme are

$$
-\mathrm{d}[\mathrm{HA} *] / \mathrm{d} t=\left(k_{1}^{\prime}+k_{f}\right)\left[\mathrm{HA}^{*}\right]-k_{2}^{\prime}\left[\mathrm{A}^{-*}\right],
$$

$$
\mathrm{d}\left[\mathrm{A}^{-*}\right] / \mathrm{d} t=k_{1}^{\prime}[\mathrm{HA} *]-\left(k_{2}^{\prime}+k_{f}^{\prime}\right)\left[\mathrm{A}^{-*}\right],
$$


where, $k_{1}^{\prime}=k_{1}\left[\mathrm{AcO}^{-}\right]$and $k_{2}^{\prime}=k_{2}[\mathrm{AcOH}]$

Using the conditions, at $t=0,\left[\mathrm{HA}^{*}\right]=\left[\mathrm{HA}^{*}\right]_{0}$ and $\left[\mathrm{A}^{-*}\right]=0$ we obtain,

$$
\begin{aligned}
& {\left[\mathrm{HA}^{*}\right](t)=} \frac{\left[\mathrm{HA}^{*}\right]_{0}}{m_{1}-m_{2}} \\
& \times\left[\left(X-m_{2}\right) \exp \left(-m_{1} t\right)+\left(m_{1}-X\right) \exp \left(-m_{2} t\right)\right], \\
& {[\mathrm{A}-*](t)=} \frac{k_{1}\left[\mathrm{AcO}^{-}\right]\left[\mathrm{HA}^{*}\right]_{0}}{m_{1}-m_{2}} \\
& \times\left[\exp \left(-m_{2} t\right)-\exp \left(-m_{1} t\right)\right],
\end{aligned}
$$
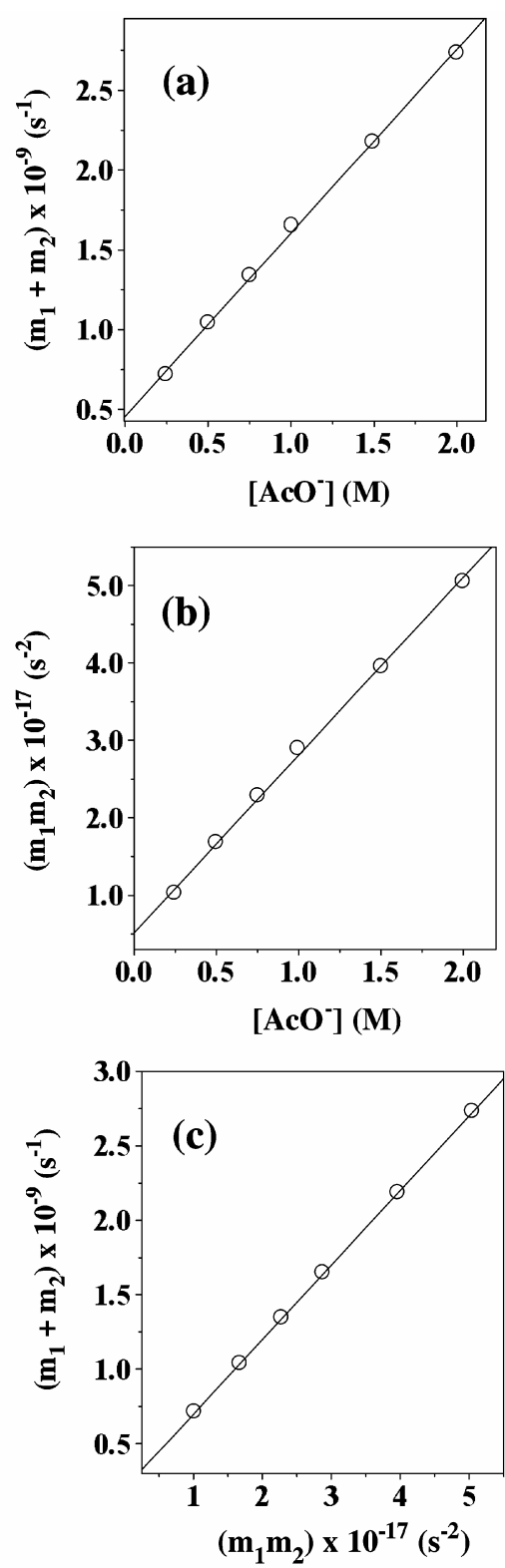

Figure 3. Plot of (a) $\left(m_{1}+m_{2}\right)$ versus [AcO $]$, (b) $m_{1} m_{2}$ versus $\left[\mathrm{AcO}^{-}\right]$and $(\mathbf{c})\left(m_{1}+m_{2}\right)$ versus $m_{1} m_{2}$ for HPTS in methanol at different acetate concentrations $(0 \cdot 25 \mathrm{M}-2 \mathrm{M})$. where $X=k_{1}^{\prime}+k_{f} \quad$ and $\quad Y=k_{2}^{\prime}+k_{f}^{\prime} \quad m_{1}=\tau_{1}^{-1}$, $m_{2}=\tau_{2}^{-1}$

$$
m_{1}, m_{2}=\frac{1}{2}\left[(X+Y) \pm\left\{(Y-X)^{2}+4 k_{1}^{\prime} k_{2}^{\prime}\right\}^{1 / 2}\right]
$$

According to the scheme discussed above, the decay of the deprotonated form at $515 \mathrm{~nm}$ should be a sum of two exponentials, whose amplitudes are equal in magnitude but opposite in sign. Moreover, the exponents of the transients at $420 \mathrm{~nm}$ and $515 \mathrm{~nm}$ should be identical, as is actually observed. However, the observed decay at $420 \mathrm{~nm}$ is found to be single exponential. This may be due to the negligible contribution of the component $\tau_{2}$ and the very small value of the recombination rate constant $\left(k_{2}\right)$, compared to that of proton transfer $\left(k_{1}^{\prime}\right)$.

The rate constants $k_{1}, k_{f}$ and $k_{f}^{\prime}$ may be evaluated using the following equations which can be derived from the scheme discussed above.

$$
\begin{aligned}
& \left(m_{1}+m_{2}\right)=k_{1}\left[\mathrm{AcO}^{-}\right]+\left(k_{f}+k_{2}^{\prime}+k_{f}^{\prime}\right), \\
& \left(m_{1}+m_{2}\right)=k_{f}+Y\left(1-\frac{k_{f}}{k_{f}^{\prime}}\right)+\frac{m_{1} m_{2}}{k_{f}^{\prime}}, \\
& m_{1} m_{2}=k_{f}^{\prime} k_{1}\left[\mathrm{AcO}^{-}\right]+k_{f} Y .
\end{aligned}
$$

As indicated in table 1 , with increase in $\left[\mathrm{AcO}^{-}\right]$, a larger amount of acetic acid is needed to suppress the absorption due to $\mathrm{A}^{-}$. Thus, $k_{2}^{\prime}\left(=k_{2}[\mathrm{AcOH}]\right)$ and hence, $Y\left(=k_{2}^{\prime}+k_{f}^{\prime}\right)$ varies with $\left[\mathrm{AcO}^{-}\right]$. Thus, the plot of $m_{1} m_{2}$ against [AcO $\left.{ }^{-}\right]$should not be a straight line. However, the excellent linearity of this plot (figure $3 b$ ) suggests that the term $k_{2}^{\prime}$ is negligible. In other words, back proton transfer is much slower than radiative decay of $\mathrm{A}^{-}$, i.e. $k_{f}^{\prime} \gg k_{2}^{\prime}$. Neglecting $k_{2}^{\prime}$, from (6)-(8) we obtain excellent linear plots of $m_{1}+m_{2}$ against $\left[\mathrm{AcO}^{-}\right]$(figure $3 \mathrm{a}$ ), of $m_{1} m_{2}$ against $\left[\mathrm{AcO}^{-}\right]$(figure 3b) and of $m_{1}+m_{2}$ against $m_{1} m_{2}$ (figure $3 \mathrm{c}$ ). The values of rate constants $k_{1}, k_{f}$ and $k_{f}^{\prime}$ are calculated from the slopes and intercepts of the plots in figure 3 . The values of $k_{1}, k_{f}$ and $k_{f}^{\prime}$ are found to be $1.0 \times 10^{9} \mathrm{M}^{-1} \mathrm{~s}^{-1}, 2.6 \times 10^{8} \mathrm{~s}^{-1}$ and $2.3 \times 10^{8} \mathrm{~s}^{-1}$.

The rate constant for quenching of HA emission by acetate is determined from a simple bimolecular quenching equation. According to this, the lifetime decay $(\tau)$ of HA in methanol decreases with quencher (acetate) concentration $[Q]$ as, 


$$
1 / \tau=1 / \tau_{0}+k_{q}[Q]
$$

where $\tau_{0}$ is the lifetime in the absence of the acetate. A typical plot of the reciprocal of lifetime of the

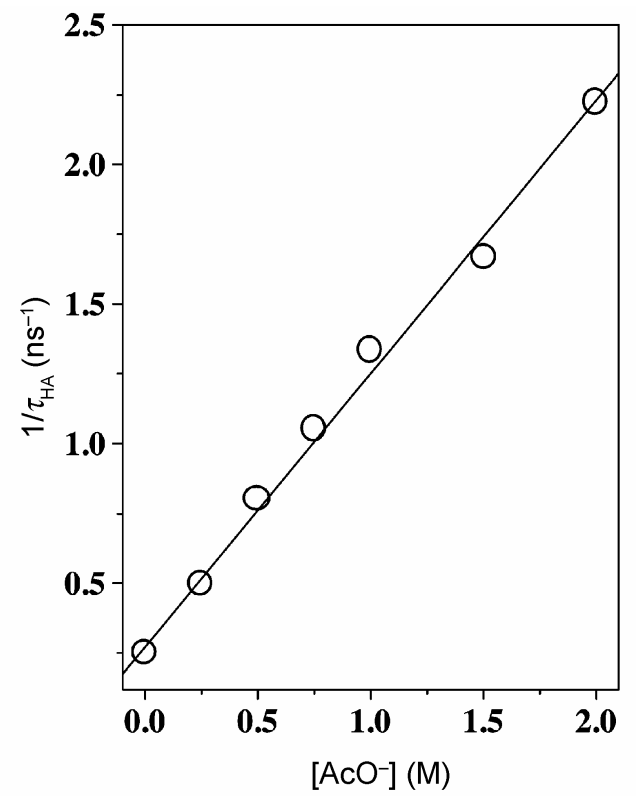

Figure 4. A plot of inverse of decay time $\left(1 / \tau_{\mathrm{HA}}\right)$ of the protonated (HA) form of HPTS against concentration of $\mathrm{AcO}^{-}$in methanol.

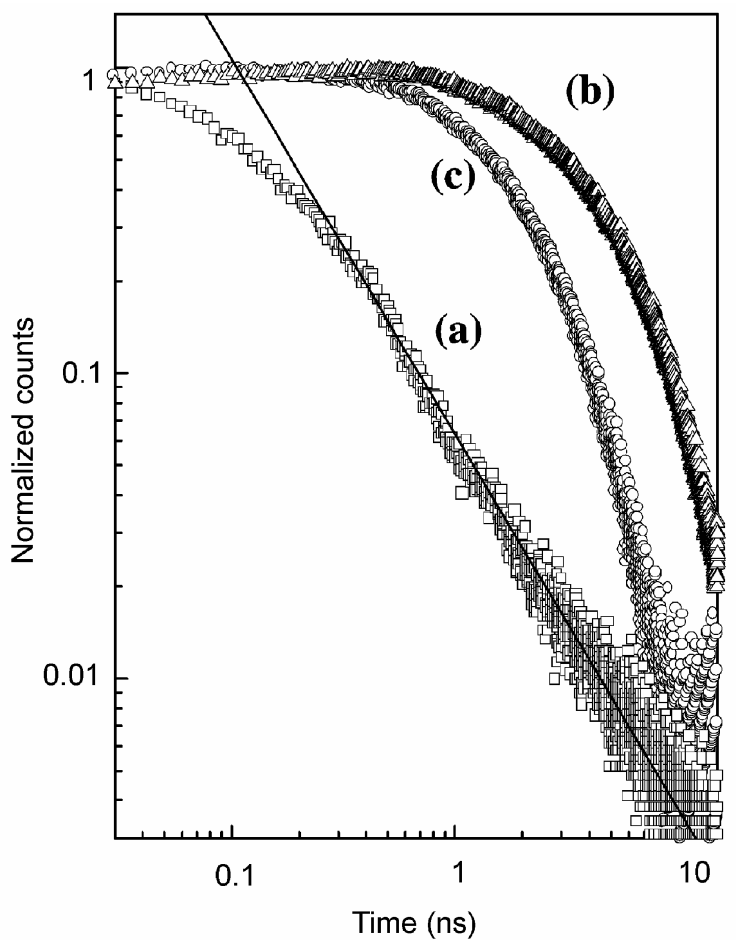

Figure 5. Log-log plot of fluorescence decay of HPTS in (a) water $\left(\lambda_{\mathrm{ex}}=405 \mathrm{~nm}, \lambda_{\mathrm{em}}=440 \mathrm{~nm}\right)$, (b) methanol $\left(\lambda_{\mathrm{ex}}=375 \mathrm{~nm}, \lambda_{\mathrm{em}}=420 \mathrm{~nm}\right)$ and (c) methanol containing $2 \mathrm{M}$ acetate $\left(\lambda_{\mathrm{ex}}=375 \mathrm{~nm}, \lambda_{\mathrm{em}}=420 \mathrm{~nm}\right)$. protonated form of pyranine (HA) against acetate concentration is given in figure 4 . The bimolecular quenching constant $k_{q}$ is found to be $0.96 \times 10^{9} \mathrm{M}^{-1} \mathrm{~s}^{-1}$.

It may be noted that the observed value of $k_{q}$ $\left(0.96 \times 10^{9} \mathrm{M}^{-1} \mathrm{~s}^{-1}\right)$ is close to the calculated value of the rate constant for proton transfer, $k_{1}(1.0 \times$ $\left.10^{9} \mathrm{M}^{-1} \mathrm{~s}^{-1}\right)$. This indicates relatively simple kinetic behaviour of HPTS in methanol.

As noted earlier, the proton transfer rate of pyranine to acetate $(4 \mathrm{M})$ in water is one of the fastest reactions investigated so far with a rate constant of $8 \times 10^{10} \mathrm{M}^{-1} \mathrm{~s}^{-1}$ [7]. The rate constant of ESPT from HPTS to acetate in a $2 \mathrm{M}$ solution of acetate in methanol is slower by $\approx 2$ orders of magnitude compared to that (ESPT to acetate) in water. The slowing down of the proton-transfer process in methanol is due to inefficient stabilization of the ejected proton and lack of solvent participation in proton transfer by the Grotthuss mechanism. ${ }^{1}$ Absence of solvent mediation hardly allows the reactants (HPTS and acetate) to come in close proximity with the proper geometry suitable for reverse proton transfer. This results in a much slower recombination rate.

According to several recent works on ESPT of HPTS, the long time-decay part of the photoacid should display power-law kinetics. The power-law $t^{-3 / 2}$ decay of the fluorescence intensity is the fingerprint of spherical symmetrical diffusion assisted reversible geminate recombination. ${ }^{16,17}$ In bulk water, the decay of HA emission clearly shows power-law behaviour at long time range for two decades of time (figure 5). This indicates the existence of geminate ion pairs in the proton-transfer process. In methanol, HPTS does not exhibit ESPT to methanol and shows a clear single-exponential decay kinetics of HA emission with no power-law decay behaviour (figure 5). On addition of acetate, when ESPT occurs, the decay of the photoacid exhibits exponential decay behaviour with no power-law decay kinetics (figure 5).

In summary, in methanol, ESPT from HPTS to acetate occurs directly without involving a geminate ion pair. The non-existence of the geminate ion-pair in the excited-state proton-transfer of HPTS to acetate in methanol may be due to the low stabilization energy of the geminate ion-pair.

\section{Conclusion}

The present work demonstrates that ESPT from HPTS to methanol does not occur because of poor stabili- 
zation of the ejected proton and the deprotonated species. In methanol, ESPT from HPTS to acetate is explained in terms of the direct proton transfer model without involving a geminate ion-pair. This is in sharp contrast to the situation in water, where both solvent-mediated and direct proton transfer between HPTS and acetate are observed, depending on the concentration of acetate ion., ${ }^{9,10}$ The rate of proton transfer from HPTS to acetate in methanol is slower by about two orders of magnitude with respect to that in water.

\section{Acknowledgements}

Thanks are due to Department of Science and Technology, India and to the Council of Scientific and Industrial Research (CSIR), New Delhi for generous research grants. SKM, SG, and KS thank the CSIR for fellowships.

\section{References}

1. Agmon N 2005 J. Phys. Chem. A109 13

2. Kuhlbrandt W 2000 Nature (London) 406569
3. Smith K K, Kaufmann K J, Huppert D and Gutman M 1979 Chem. Phys. Lett. 64522

4. Tran-Thi T H, Prayer C, Millie P, Uznanski P and Hynes J T 2002 J. Phys. Chem. A106 2244

5. Tran-Thi T H, Gustavsson T, Prayer C, Pommeret $\mathrm{S}$ and Hynes J T 2000 Chem. Phys. Lett. 329421

6. Mohammed O, Pines D, Dryer J, Pines E and Nibbering E T J 2005 Science 31083

7. Genosar L, Cohen B and Huppert D 2000 J. Phys. Chem. A104 6689

8. Cohen B, Leiderman P and Huppert D 2003 J. Luminescence 102682

9. Rini M, Magnes B-Z, Pines E and Nibbering E T J 2003 Science 301349

10. Rini M, Pines D, Magnes B-Z, Pines E and Nibbering E T J 2004 J. Chem. Phys. 1219593

11. Mondal S K, Sahu K, Sen P, Roy D, Ghosh S and Bhattacharyya K 2005 Chem. Phys. Lett. 412228

12. Sahu K, Roy D, Mondal S K, Karmakar R and Bhattacharyya K 2005 Chem. Phys. Lett. 404341

13. Mondal S K, Sahu K, Ghosh S, Sen P and Bhattacharyya K 2007 J. Phys. Chem. (in press)

14. Shizuka H 1985 Acc. Chem. Res. 18141

15. Loken M R, Hayes J W, Gohlke J R and Brand L 1972 Biochemistry 114779

16. Agmon N, Pines E and Huppert D 1988 J. Chem. Phys. 885631

17. Leiderman P, Genosar L and Huppert D 2005 J. Phys. Chem. A109 5965 